Rev. Interd. em Cult. e Soc. (RICS), São Luís, v. 6, n. 2, p. 50-71, jul./dez. 2020

ISSN eletrônico: $2447-6498$

\title{
La cuestión del cuidado en el escenario post pandemia. ¿Hacia Estados del Cuidado o hacia Gilead? ${ }^{1}$
}

\section{The issue of care in the post-pandemic setting. Towards States of Care or Gilead?}

\author{
SILVIA LILIAN FERRO \\ Cientista Social e professora \\ Instituto Latino-americano de Economia, Sociedade e Política (ILAESP) \\ Universidade Federal da Integração Latino-americana (UNILA). \\ lilian.ferro@unila.edu.br
}

\section{RESUMEN}

Esta comunicación se propone analizar el impacto de la pandemia por COVID 19 en la preexistente crisis global del cuidado, que afecta también a sociedades latino-americanas. Seguidamente, se realiza análisis prospectivo buscando identificar elementos del presente con potencial de proyección al futuro inmediato y mediato, que puedan reconfigurar en forma duradera aspectos estructurales en la organización social del cuidado La metodología es comparativa, considerando estudios en perspectiva de género realizados por organismos multilaterales, áreas estatales y por organizaciones de la sociedad civil, así como estadísticas oficiales. Se colocan estos resultados provisorios en diálogo epistemológico con literatura académica de referencia en el tema. Los resultados presentan posibles alternativas dicotómicas en el escenario post-pandemia: elevación del cuidado a categoría política y ethos civilizatorio materializado en formas de Estado ad hoc, o el retorno al patriarcado como lógica absoluta para la convivencia humana, esta vez en nombre de la racionalidad sanitaria.

Palabras claves: Pandemia. Prospectiva. Crisis global de cuidados. Distopia. América Latina.

\begin{abstract}
This communication aims to analyze the impact of the COVID 19 pandemic on the pre-existing global care crisis, which also affects Latin American societies. Next, prospective analysis is carried out seeking to identify elements of the present with potential for projection into the immediate and mediate future, which can permanently reconfigure structural aspects in the social organization of care. The methodology is comparative, considering studies from a gender perspective carried out by multilateral organizations, state areas and by civil society organizations, as well as official statistics. These provisional results are placed in an epistemological dialogue with academic reference literature on the subject. The results present possible dichotomous alternatives in the post-pandemic scene: elevation of care to political category and a civilizing ethos materialized in forms of State ad hoc, or the return to patriarchy as an absolute logic for human coexistence, this time in the name of rationality sanitary.
\end{abstract}

Keywords: Pandemic. Prospective. Global crisis of care. Distopia. Latin America.

\section{1-INTRODUCCIÓN}

Luego de los primeros meses de declarada la pandemia en el mundo, en marzo del corriente año, diversos organismos internacionales y estatales comienzan a evaluar los

\footnotetext{
${ }^{1}$ Artigo recebido em: 25.09.2020 e aprovado em: 30.10.2020.
} 
Rev. Interd. em Cult. e Soc. (RICS), São Luís, v. 6, n. 2, p. 50-71, jul./dez. 2020

ISSN eletrônico: $2447-6498$

primeros impactos de las medidas de aislamiento social, preventivo y obligatorio en la convivencia dentro de los hogares, medidas impuestas en la mayor parte de las sociedades del mundo y por ende también latinoamericanas, debido a que la respuesta generalizada por parte de los gobiernos, en las primeras etapas de las llamadas cuarentenas fue, como su nombre lo indica, mantener a la mayor parte de la población confinada en sus hogares el mayor tiempo posible. En común, estos estudios apuntan el incremento de las situaciones de violencia de género y doméstica en todas sus dimensiones (UN WOMEN,2020). Si bien la violencia de género y doméstica se percibía previamente en permanente crecimiento debido a diversos factores, esta crisis sanitaria global en concreto provocó una intensificación del problema,

Durante las emergencias sanitarias, como la pandemia de COVID-19, la violencia contra la mujer tiende a aumentar [...]según informes de diferentes países del mundo, entre ellos China, el Reino Unido y los Estados Unidos de América, parece que se ha producido un aumento considerable en el número de casos de violencia doméstica en relación con la pandemia de la COVID19. En informes de otros países se apunta a una disminución en el número de víctimas que solicitan ayuda debido a las medidas de confinamiento y al miedo a infectarse en los centros de atención sanitaria. (WHO,2020²).

Ni las pandemias, ni las cuarentenas son novedosas en la historia humana. Según Harari (2018) el paso de la caza recolección nómada a la vida sedentaria y al agrupamiento en ciudades, a consecuencia de la primera revolución agrícola hace por lo menos entre 12.000 y 10.000 antes de nuestra era, creó las condiciones para que éstas existieran. Inicialmente ocurridas como consecuencias de guerras y matanzas según relatan Heródoto y Tucídides (apud CZERESNIA 1997, p.41-43) pronto fueron consideradas castigos divinos como relata Ovidio (p.43-44) tanto en contextos paganos pre cristianos como en la propia etapa cristiana. Ejemplo de esto último es lo que informan Lovell y Cook (2000) al respecto de epidemias introducidas, involuntariamente, por los cuerpos de europeos y de los animales originarios de diversos ecosistemas en los territorios americanos durante la conquista y colonización de las Américas. Ante la constatación de que las enfermedades que se originaron en esos contactos como viruela, el sarampión y la influenza mataban exponencialmente más indígenas que europeos $^{3}$, fueron consideradas-y aprovechadas para objetivos de dominación colonial- como castigos del Dios cristiano por el paganismo y la resistencia a la evangelización por parte de los indígenas. J. Diamond plantea en su influyente libro Armas, gérmenes y acero. El destino de las sociedades humanas (2013) que esta asimetría en la morbilidad y mortalidad causada

\footnotetext{
${ }^{2}$ Extraído de https://www.who.int/es/news-room/q-a-detail/violence-against-women-during-covid-19

${ }^{3}$ Una de las explicaciones más aceptadas para este fenómeno, es la de epidemias de suelo virgen. La presencia o la falta de inmunidad adquirida a vectores específicos, determinaría que la misma enfermedad para algunos grupos se manifieste en forma leve y sea tratable y para otros, sin esa adaptación inmunológica previa, sea letal. (LOVELL y COOK, 2000)
} 
Rev. Interd. em Cult. e Soc. (RICS), São Luís, v. 6, n. 2, p. 50-71, jul./dez. 2020

ISSN eletrônico: 2447-6498

por enfermedades introducidas por los europeos fue decisiva en la consolidación de la conquista y colonización, así como en la cristianización de las sociedades originarias americanas.

A lo largo de nuestro tiempo, "[...] as epidemias ${ }^{4}$ tendem a se suceder umas às outras em séries regulares e circulares." (CZERESNIA, 1997, p.81) generando o actualizando controversias morales, políticas, sociales y científicas, dando lugar a cambios profundos y duraderos en las ideas que prevalecerán sobre las formas más convenientes de organización $a$ posteriori de la convivencia humana.

En la actual pandemia, lo que podría considerarse innovador es la atención desde una perspectiva de género, que están prestando autoridades públicas, organizaciones de la sociedad civil y medios de comunicación a las consecuencias que estas medidas traen dentro de los hogares. Por perspectiva de género se entiende aquí al análisis de la realidad social desde la categoría género considerada: "[...] elemento constitutivo de las relaciones sociales basadas en las diferencias percibidas entre los sexos y el género es una forma primaria de relaciones significantes de poder." (SCOTT, 1996, p.23) Esa atención, aun con las insuficiencias o limitaciones que puedan señalarse sobre ella, es una conquista de la intensa movilización social, epistemológica y política surgida con la propia Modernidad (AMORÓS, 2005) protagonizada por los movimientos feministas y de mujeres, contando también con eventuales o coyunturales aliados. En el presente, consiguen colocar en las agendas reivindicativas y de demandas hacia la acción pública de los estados y hacia la sociedad en general, la comprensión respecto a que las asimetrías entre hombres y mujeres en los espacios públicos y domésticos y sus consecuencias negativas, además de no "naturales", son un problema de orden político, económico, social y cultural y no apenas moral o de estricta incumbencia de "acuerdos" en el marco de los vínculos interpersonales y familiares, es decir privados.

Tal conquista, no fue apenas una cuestión de superioridad retórica o de mejores lógicas argumentativas en el debate público, sino que fue fundamental que se haya superado

\footnotetext{
${ }^{4}$ La diferencia entre los términos pandemia, epidemia y endemia tiene que ver con su ámbito y velocidad de diseminación y no estrictamente con la cantidad de casos concentrados en una región. (DE REZENDE,1998). En ese sentido y siguiendo a Lovell y Cook (2000) podría afirmarse que desde el siglo XVI en la etapa colonial americana hubo pandemias, aunque comúnmente se las denomine epidemias, porque vectores y huéspedes pertenecían a diferentes continentes, como inicialmente ocurrió con el COVID 19 y porque los focos de las enfermedades se propagaron a pueblos originarios situados en regiones distantes dentro del continente.

${ }^{5}$ Para los neoclásicos hombres y mujeres pactarían desenvolverse en ámbitos diferenciados por cuenta de las ventajas comparativas que les brindan sus diferentes especializaciones (BECKER apud FERRO, 2017). Ellos: en el espacio público-remunerado y reconocido como trabajo con derechos laborales y previsionales emergentes. Ellas: en el ámbito doméstico, no remunerado ni reconocido como trabajo, por ende, sin derechos laborales y previsionales asociados.
} 
Rev. Interd. em Cult. e Soc. (RICS), São Luís, v. 6, n. 2, p. 50-71, jul./dez. 2020

ISSN eletrônico: $2447-6498$

el mero plano reivindicativo y ético en la inscripción de esas demandas, para pasar a la estrategia de demostrar las profundas consecuencias demográficas, económicas y de todo orden que ocasiona ignorar este problema en todas las sociedades contemporáneas. La matrix de la desigualdad en las oportunidades entre hombres y mujeres que perdura en cada ámbito de actividad humana, se origina en la asimetría en la distribución de las responsabilidades del cuidado familiar.

La pandemia de la enfermedad por coronavirus (COVID-19) ha puesto de relieve, de forma inédita, la importancia de los cuidados para la sostenibilidad de la vida y la poca visibilidad que tiene este sector en las economías de la región, en las que se sigue considerando una externalidad y no un componente fundamental para el desarrollo. (NU CEPAL, 20206).

Por trabajos de cuidados se entiende aquí al conjunto de prestaciones, tanto individuales, como grupales y colectivas que generan servicios altamente personalizados y que demandan inmensas inversiones de tiempos, energías físicas y especialización ${ }^{7}$. Estos servicios de cuidados garantizan el bienestar biológico, psicológico, social y espiritual de otras personas que se benefician de ellos; sean prestados en forma remunerada como gratuita, sean prestados en hogares como en espacios públicos (FERRO, 2019) ${ }^{8}$ : "Particularmente, en nuestras sociedades occidentales industrializadas, la subsistencia y calidad de vida se nutre fundamentalmente de tres fuentes: las producciones y actividades de cuidados directos realizadas desde el hogar, el mercado y la oferta de servicios públicos.” (CARRASCO, 2001, p.2).

Su dimensión económica, más allá de social y política, es tan evidente como poco abordada: "desde una perspectiva socioeconómica, al menos para la economía oficial el sostenimiento de la vida no ha sido nunca una preocupación analítica central” (p.5). Hasta nuestros días son prestados mayoritariamente por mujeres en atención a un orden de ideas y de prácticas culturales que atribuyen a hombres y mujeres responsabilidades diferentes en los trabajos y actividades de sostenimiento de la vida humana. Prácticas que intentan justificarse en la diferencia biológica entre los sexos y a las que feministas marxistas han denominado "división sexual del trabajo". De esta división seguiría la adscripción de las mujeres al trabajo de cuidados familiares, liberando a los hombres de estos y hasta del cuidado de sí mismos

\footnotetext{
${ }^{6}$ Extraído de: https://www.cepal.org/es/publicaciones/45335-la-pandemia-covid-19-profundiza-la-crisiscuidados-america-latina-caribe

${ }^{7}$ La "especialización" en el trabajo de cuidados es una cuestión muy debatida porque es una palabra que se identifica con saberes técnicos y científicos acreditados. En la perspectiva teórica de esta investigación se entiende por especialización a la personalización, o sea a la adaptación a características y preferencias del destinatario de esos servicios.

${ }^{8}$ En el enfoque de este trabajo se considera que el trabajo de cuidados incluye al trabajo doméstico y al trabajo reproductivo, por tanto, con dicha expresión se refiere a ambas dimensiones.
} 
Rev. Interd. em Cult. e Soc. (RICS), São Luís, v. 6, n. 2, p. 50-71, jul./dez. 2020

ISSN eletrônico: $2447-6498$

para que optimicen sus tiempos, energías y creatividad en los espacios públicos. Esta asimétrica distribución de las responsabilidades del cuidado familiar y comunitario, está claramente identificada en las estadísticas públicas, a través de las Encuestas de Uso del Tiempo (Time's budgets) que miden la distribución del tiempo de hombres y mujeres en trabajo remunerado y no remunerado.

Gráfico No. 1 América Latina (16 países): Tiempo promedio semanal destinado al trabajo remunerado y no remunerado de la población desde 15 años, por sexo y país, último período disponible.

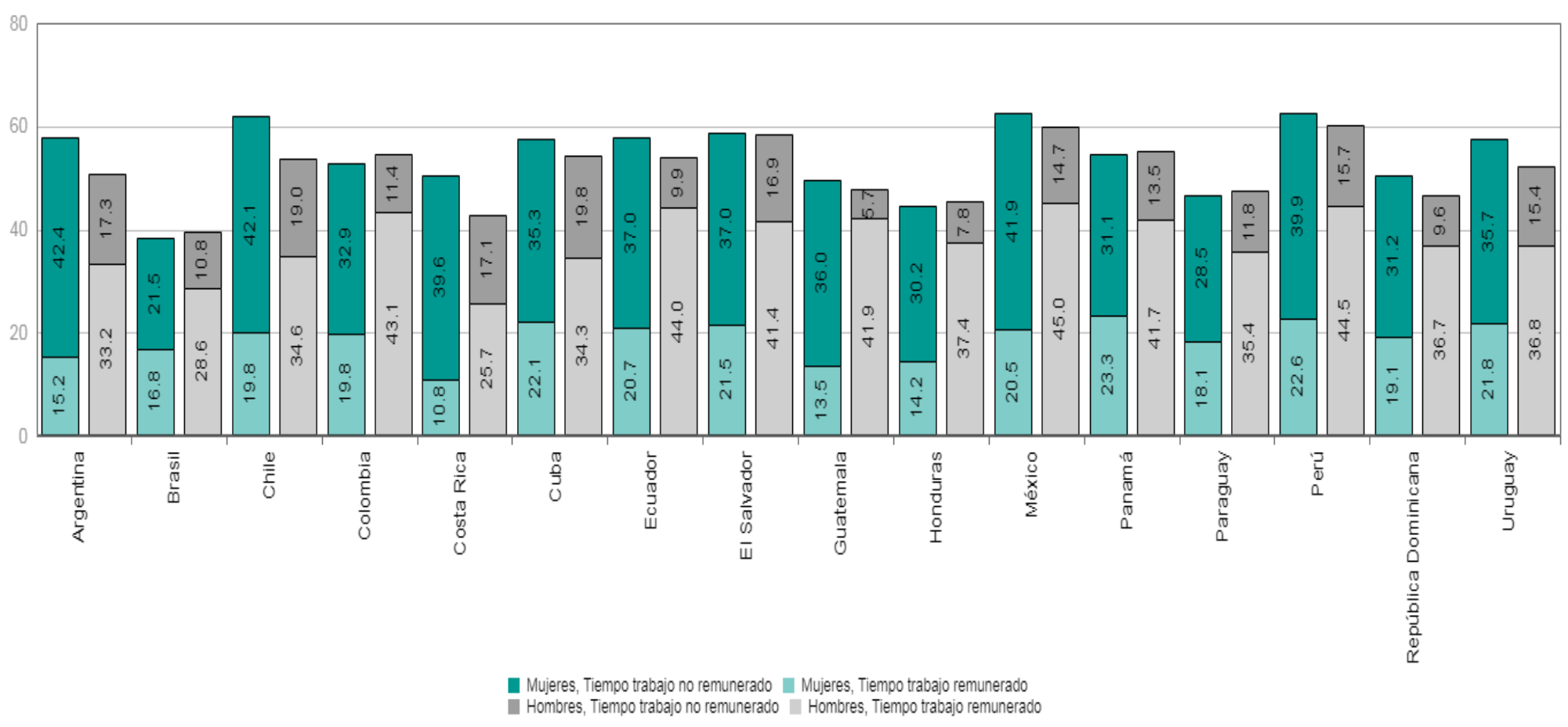

Fuente: https://oig.cepal.org/pt/indicadores/tempo-total-trabalho ${ }^{9}$.

La informalidad y extrema precariedad que caracteriza al empleo doméstico (trabajo de cuidados remunerado) en el mundo y más aún en los países aquí considerados, hace muy difícil contar con indicadores que lo dimensionen con una aproximación más precisa en cuanto a su gravitación en el conjunto del trabajo asalariado, al igual que el trabajo de cuidados familiar no remunerado, este también se encuentra ampliamente feminizado:

En América Latina y el Caribe, entre 11 y 18 millones de personas se dedican al trabajo doméstico remunerado. De ellas el $93 \%$ son mujeres. El trabajo doméstico supone entre el $14,3 \%$ y el $10,5 \%$ del empleo de las mujeres en la región. Sin embargo, más del 77,5\% operan en la informalidad, lo que significa que una parte importante de ellas trabaja en condiciones precarias y sin acceso a la protección social. Los ingresos de las mujeres empleadas en el servicio doméstico son además

\footnotetext{
${ }^{9}$ Acceso en septiembre 2020
} 
Rev. Interd. em Cult. e Soc. (RICS), São Luís, v. 6, n. 2, p. 50-71, jul./dez. 2020

ISSN eletrônico: 2447-6498

iguales o inferiores al 50\% del promedio de todas las personas ocupadas. (CEPAL, $\left.2020^{10}\right)$.

Esta asimetría estructural en los hogares se proyecta a los mercados laborales en la forma de segregaciones laborales, horizontales y verticales, así como en la pervivencia de desigualdades salariales entre hombres y mujeres; más acentuadas en países latinoamericanos (LARRAITZ et. al; 2019) y que intentan ser superadas por las mujeres, en todas partes, con el plus educativo (UNESCO, 2019) Se esperaría que este plus educativo haga más difícil la discriminación por razones de género por parte de los empleadores, tanto en la contratación como en la movilidad ascendente dentro de las organizaciones, incluso de aquellas también ampliamente feminizadas en términos absolutos y relativos (GALVEZ,2006). Esta feminización también ocurre en las llamadas ocupaciones front line (línea de frente) así consideradas porque implican un constante contacto e interacción con personas usuarias y demandantes de servicios diversos, cuya precariedad tradicional se ve acompañada ahora de una mayor exposición al riesgo de contagio,

Frontline occupations are defined as those involving close face-to-face contacts with consumers, clients, and patients, or where social distancing is impossible (e.g., meat-processing plants). Frontline workers are poorly paid, are disproportionately African American, Hispanic, and female, and are also less likely to have health insurance than workers in other occupations. (HRSA, 2017, p. 01).

Por ello, esta propuesta pretende analizar una selección de medidas, políticas y teorías en el marco de esta pandemia que tengan proyección al futuro mediato e inmediato de nuestras sociedades, después de superadas las estrategias de cuarentenas tanto permanentes como eventualmente intermitentes. Escenarios anticipados por líderes de opinión con el nombre de "nueva normalidad", considerando el punto de partida en cada caso con apoyo de estimaciones estadísticas.

\section{2- LIMITACIONES DE LA RACIONALIDAD SANITARIA}

La secularización de la sociedad a consecuencia del impacto de las ideas de la Ilustración a partir del siglo XVIII en Occidente, implicó también un ascenso de la Medicina de la mano de los incipientes estados nacionales para coprotagonizar acciones regulatorias del buen funcionamiento de los cuerpos, en tanto materialidad de la población y materia prima de la ciudadanía: "En este sentido, las normas religiosas de una buena vida fueron

\footnotetext{
${ }^{10}$ Extraído de: https://www.cepal.org/es/noticias/la-situacion-precariedad-trabajadoras-domesticas-americalatina-caribe-se-acentua-frente-la
} 
Rev. Interd. em Cult. e Soc. (RICS), São Luís, v. 6, n. 2, p. 50-71, jul./dez. 2020

ISSN eletrônico: 2447-6498

transferidas a la medicina; el resultado es que esta como ciencia supuestamente neutra, sobrepasa los límites tanto del derecho como de la religión al proveer de criterios de normalidad" (TURNER, 2014, p. 283).

Nacía también a partir de esa etapa, una "división sexual" del cuidado de la supervivencia biológica del cuerpo: el cuidado institucionalizado y reconocido como saber técnico-científico pasará a llamarse medicina, para diferenciarse del cuidado de la supervivencia biológica del cuerpo que se realiza en los hogares, mayormente por parte de las mujeres y que pierde su estatus de saber-hacer para pasar a ser apenas actos reflejos del repertorio de instintos de la animalidad femenina. Por ejemplo, los cuidados que dan las mujeres en las etapas más críticas para la supervivencia humana desde el momento en que nacemos hasta que conseguimos una relativa autonomía corporal son considerados "instintos maternos". Una reacción instintiva es irracional y no controlable por la voluntad humana por tanto es antítesis del saber racional, entre otros el de la medicina occidental que desde el siglo XVIII se basa, en gran medida, en el paradigma experimental de las ciencias naturales y en la lógica cartesiana. En términos cuantitativos y cualitativos, los cuerpos llegan a la esfera de la medicina cuando previamente fueron beneficiados por cuidados familiares recibidos durante periodos de tiempos exponencialmente mayores. Quienes los cuidaron han sabido hacer con experticia, eficiencia y eficacia en la generalidad de los casos, para mantener esos cuerpos con vida desde el momento del nacimiento.

La profesionalización de la medicina impulsada desde que asume la función de brazo regulador de la gobernanza estatal sobre los cuerpos de sus ciudadanos. Este nuevo orden de cosas desplazó tempranamente a las mujeres de su amplia incidencia sobre el cuidado de la salud tanto por parte de las madres y otras mujeres de la familia ampliada en la cotidianeidad por parte de parteras y curanderas en los momentos más decisivos del ciclo de la vida humana que se expresan principalmente a través de la corporalidad: gravidez, nacimiento, enfermedad y muerte; sacándolos de la esfera doméstica para llevarlos al hospital bajo la tutela estatal: "El Estado regula el cuerpo por medio de la interferencia de una variedad de aparatos ideológicos, especialmente por medio del Derecho de Familia y de la medicina preventiva." (TURNER, 2014, p. 283).

Aun así, el cuidado de las personas llevado a cabo gratuitamente principalmente por las mujeres en los hogares y en menor medida en el espacio público, no fue simplemente ignorado durante el ascenso político del sanitarismo. Durante el siglo XIX el Higienismo, comienza a mirar con detenimiento a la vida doméstica como parte de las condiciones de vida colectivas de los sectores populares: "Certas condições de vida, contudo, dizem respeito a 
Rev. Interd. em Cult. e Soc. (RICS), São Luís, v. 6, n. 2, p. 50-71, jul./dez. 2020

ISSN eletrônico: 2447-6498

nações inteiras ou a maior parte da população, e enquanto os indivíduos nas suas vidas particulares sempre são os portadores e a expressão de situações e condições, normais e anormais" (VIRCHOW apud CZERESNIA, 1997, p.57). El higienismo ejerció y lo sigue haciendo, la tutela técnico-científica de los trabajos de cuidados que llevan a cabo las irracionales en los hogares. Mientras la medicina pública al servicio del Estado y de los particulares, fue durante mucho tiempo ejercida por hombres mayoritariamente, siendo remunerada y reconocida socialmente como trabajo y como saber científico; quienes mantienen los cuerpos sanos y con vida en forma cotidiana con su tiempo, energías y especialización en los hogares (FERRO, 2020) lo hacen a título honorario en cuanto mujeres, dotadas "naturalmente" para ello.

Más adelante, en 1946, la naciente Organización Mundial de la Salud (WHO según sigla en inglés) en su Constitución firmada por 61 países, proclama una definición de salud de reminiscencias hipocráticas: "La salud es un estado de completo bienestar físico, mental y social, y no solamente la ausencia de afecciones o enfermedades" (WHO, 2006). De cualquier definición con alcance normativo se desprenden los procedimientos y políticas reconocidas como legítimas. Considerando la integralidad de aspectos que recoge esta definición no se entiende como la producción y preservación de un "estado" de salud quedó- en su connotación operacional-circunscripta al sistema sanitario institucionalizado, porque aún la "ausencia de afecciones y enfermedades" le debe más al cuidado familiar que al cuidado institucionalizado, en la mayoría de los casos y en forma sistémica.

Dicho de otra manera, no se entiende como el cuidado quedó fuera del espacio epistemológico y especialmente procedimental del sanitarismo, siendo el componente más extenso, masivo y perdurable de la producción y sostenimiento de un "estado" de salud. Lo sanitario es a la salud humana lo que los talleres mecánicos son al funcionamiento de los vehículos a motores: una eventualidad, que existe solo porque los vehículos funcionan ex ante, participando episódicamente-arreglando fallos de fábrica o adquiridos por el uso- sin negar su importancia para la durabilidad de los mismos y los valiosos consejos que brindan para administrar los naturales desgastes y prevenir funcionamientos erróneos. Por ello, se considera reductivo el enfoque de género que se evidencia en las principales organizaciones multilaterales que orientan políticas de salud de los países miembros, cuando consideran bajo el nombre "enfoque de género" apenas cuestiones procedimentales como el acceso al sistema por parte de hombres y mujeres o el impacto de medidas de salud pública, sin cuestionar la forma sesgada en que se construyen las definiciones que las originan y direccionan que opacan la gravitación del cuidado, dejando notar apenas el cuidado institucionalizado. 
Rev. Interd. em Cult. e Soc. (RICS), São Luís, v. 6, n. 2, p. 50-71, jul./dez. 2020

ISSN eletrônico: $2447-6498$

En el presente pandémico, las ideas iniciadas por el Higienismo, sumándose las contribuciones y controversias de la Epidemiología siguen ejerciendo tutela moral y epistemológica sobre el trabajo de cuidados. Tales mensajes, lejos de desenfocarse apenas en las mujeres para así democratizar incluyendo a los hombres, se hicieron omnipresentes y más "generizados" todavía debido a la sinergia, desde el siglo pasado cuanto menos y sin solución de continuidad en el presente, con intereses mercantiles de las industrias químicas y farmacológicas Para comprobar esto basta ver los contenidos factuales y simbólicos de la publicidad de productos de limpieza y de insumos y servicios para la crianza, están casi siempre dirigida hacia las mujeres en forma directa y que además idealizan, una fisonomía laboratorial del hogar para connotar eficiencia y eficacia de la higiene doméstica y del cuidado de los cuerpos. La limpieza de la casa/habitación de los núcleos de convivencia, asume la fisonomía de una batalla química, parte de una guerra sin cuartel contra gérmenes, virus y bacterias que forman parte del séquito indeseable, aunque convenientemente invisible, del funcionamiento del cuerpo humano tanto en la salud como en la enfermedad, como ocurre en el cuerpo de cualquier otro animal.

\section{EL ESCENARIO PRE PANDEMIA}

Diversos campos de la actividad humana reflejan las consecuencias de esta matriz de desigualdad, especialmente en la atribución de reconocimientos, ingresos y poder, por parte de religiones, empresas, gobiernos, ciencia, arte etc. que privilegian a aquellos integrantes, quienes además de la formación, carisma y la creatividad que eventualmente posean, generalmente están libres de responsabilidades de cuidados de otros y hasta de sí mismos, facilitando de esa forma, su desempeño full time en roles de conducción y liderazgo. Este orden de cosas viene siendo contestado por las mujeres desde antaño y también en algunos casos, menos numerosos o visibles, por hombres con sentido de justicia ${ }^{11}$.

Las tensiones resultantes por el uso del tiempo se expresan en comportamientos demográficos y migratorios caracterizando lo que se ha llamado crisis global de cuidados (PÉREZ OROZCO, 2006). En el último tercio del siglo XX comienza a visibilizarse un problema de alcance global, conocido como "internacionalización del cuidado" (PARELLO RUBIO, 2005) y también llamado transnational circuits of care (ROMERO, 2018)

\footnotetext{
11 Una de las obras más influyentes en las primeras olas feministas es La sujeción de la Mujer (1869) del economista y político liberal británico John Stuart Mill, donde denuncia la construcción social de la desigualdad entre hombres y mujeres. Juristas, religiosos y otros hombres de cultura, también harían públicas denuncias sobre la injusticia de la situación subordinada de las mujeres en sus sociedades.
} 
Rev. Interd. em Cult. e Soc. (RICS), São Luís, v. 6, n. 2, p. 50-71, jul./dez. 2020

ISSN eletrônico: $2447-6498$

aludiendo a los flujos migratorios feminizados en dirección Sur-Norte Global ${ }^{12}$, destinados a cubrir en forma remunerada el déficit de prestaciones de cuidados familiares gratuitos en los hogares de países de destino. Este déficit reconoce tres factores principales:1)la falta de democratización a escala interpersonal del reparto de las responsabilidades de los trabajos de cuidados entre hombres y mujeres que participan en el mercado laboral en forma casi paritaria en tales sociedades, 2) escasa e insuficiente infraestructura pública de servicios de cuidados, 3) desfase entre el poder adquisitivo de los salarios con las expectativas de consumo (PICCHIO, 2009) especialmente aquellas expectativas provenientes del cambio tecnológico.

Por infraestructura pública de servicios de cuidados se entiende aquí al conjunto de prestaciones gratuitas o remuneradas de acceso universalizado, financiadas $\mathrm{y} / \mathrm{u}$ operacionalizadas tanto estatalmente como por organizaciones de la sociedad civil y en todos los casos reguladas por el Estado. Por ejemplo y sin agotar inventario jardines de infantes, casas cuna, hogares de ancianos, instituciones de apoyo para personas con discapacidad, etc.

Cuadro No. 1. Sistemas universales de provisión de cuidados

\begin{tabular}{|c|c|c|c|c|c|}
\hline \multirow{2}{*}{$\begin{array}{c}\text { Subsistemas / } \\
\text { tipologias }\end{array}$} & \multirow{2}{*}{$\begin{array}{l}\text { Cuidados } \\
\text { familiares }\end{array}$} & \multirow{2}{*}{$\begin{array}{c}\text { Cuidados } \\
\text { remunerados no } \\
\text { institucionaliza } \\
\text { dos }\end{array}$} & \multicolumn{3}{|c|}{ Cuidados institucionalizados } \\
\hline & & & $\begin{array}{l}\text { Cuidados } \\
\text { estatales }\end{array}$ & $\begin{array}{c}\text { Cuidados } \\
\text { comunitarios }\end{array}$ & $\begin{array}{c}\text { Cuidados } \\
\text { empresariales }\end{array}$ \\
\hline $\begin{array}{l}\text { Local de las } \\
\text { prestaciones }\end{array}$ & $\begin{array}{l}\text { Provistos en } \\
\text { los hogares } \\
\text { entre personas } \\
\text { vinculadas por } \\
\text { parentesco. }\end{array}$ & $\begin{array}{l}\text { Provistos } \\
\text { generalmente en } \\
\text { los hogares de los } \\
\text { demandantes y en } \\
\text { ámbitos extra- } \\
\text { domésticos. }\end{array}$ & $\begin{array}{l}\text { Provistos en la } \\
\text { institucionalidad } \\
\text { pública, estatal, } \\
\text { p.e.: sistema de } \\
\text { salud pública y } \\
\text { privada, } \\
\text { alimentación y } \\
\text { otros cuidados en } \\
\text { el ámbito } \\
\text { educacional } \\
\text { público. } \\
\text { Casas de acogida, }\end{array}$ & $\begin{array}{l}\text { Generalmente } \\
\text { provistos en } \\
\text { espacios extra } \\
\text { domésticos, en } \\
\text { los locales de las } \\
\text { (o por las) } \\
\text { Organizaciones } \\
\text { de la Sociedad } \\
\text { Civil: Iglesias, } \\
\text { Cooperativas, } \\
\text { Sindicatos etc. }\end{array}$ & $\begin{array}{l}\text { Generalmente } \\
\text { provistos en } \\
\text { espacios extra } \\
\text { domésticos, en } \\
\text { los locales de las } \\
\text { (o por las) } \\
\text { empresas } \\
\text { especializadas en } \\
\text { servicios de } \\
\text { cuidados: p.e. } \\
\text { sistema de salud } \\
\text { privado y de }\end{array}$ \\
\hline
\end{tabular}

\footnotetext{
${ }^{12}$ No es casual que gran parte de la literatura de referencia del ámbito hispanohablante sobre migraciones para cuidados se haya desarrollado principalmente en España. Este país fue destino prioritario de migrantes latinoamericanas en el último tercio del siglo pasado, por la facilitación cultural de la lengua común por razones coloniales, como señala Williams (2011) para explicar los flujos de migraciones Sur-Norte Global en el siglo pasado:" These migration trails transect older tracks from colonial relations - Ethiopians to Italy, Indian and African workers to the UK, South American workers to Spain...” (p.23).
} 
Rev. Interd. em Cult. e Soc. (RICS), São Luís, v. 6, n. 2, p. 50-71, jul./dez. 2020

ISSN eletrônico: $2447-6498$

\begin{tabular}{|c|c|c|c|c|c|}
\hline & & & $\begin{array}{l}\text { cuidados } \\
\text { prestados en los } \\
\text { sistemas } \\
\text { prisionales, etc. }\end{array}$ & & $\begin{array}{l}\text { acogimiento } \\
\text { remunerado de } \\
\text { de un amplio } \\
\text { abanico de } \\
\text { necesidades de } \\
\text { cuidados. }\end{array}$ \\
\hline $\begin{array}{l}\text { Caracterización de } \\
\text { los prestadores }\end{array}$ & $\begin{array}{l}\text { Provistos casi } \\
\text { en su totalidad } \\
\text { por las } \\
\text { mujeres } \\
\text { adolescentes, } \\
\text { adultas y } \\
\text { ancianas del } \\
\text { grupo familiar. }\end{array}$ & $\begin{array}{l}\text { Provistos casi en } \\
\text { su totalidad por } \\
\text { mujeres } \\
\text { adolescentes, } \\
\text { adultas y } \\
\text { ancianas. }\end{array}$ & Feminizados $^{13}$ & Feminizados & Feminizados \\
\hline Retribución & Gratuitos & $\begin{array}{l}\text { Negociada } \\
\text { generalmente en } \\
\text { forma individual y } \\
\text { directa entre quien } \\
\text { demanda y quién } \\
\text { oferta. } \\
\text { Salarios entre los } \\
\text { más bajos en el } \\
\text { mercado laboral. }\end{array}$ & $\begin{array}{l}\text { Remunerados en } \\
\text { base a tablas } \\
\text { salariales } \\
\text { establecidas } \\
\text { legalmente para } \\
\text { cada sector } \\
\text { laboral. }\end{array}$ & $\begin{array}{l}\text { Gran parte de } \\
\text { ellos gratuitos } \\
\text { bajo la figura de } \\
\text { voluntariado } \\
\text { social. }\end{array}$ & $\begin{array}{l}\text { Remunerados en } \\
\text { base a tablas } \\
\text { salariales } \\
\text { establecidas } \\
\text { legalmente para } \\
\text { cada sector } \\
\text { laboral y } \\
\text { generalmente } \\
\text { destinados a } \\
\text { quintiles medios } \\
\text { y superiores da } \\
\text { estructura socio- } \\
\text { económica }\end{array}$ \\
\hline $\begin{array}{c}\text { Regulaciones } \\
\text { normativas }\end{array}$ & $\begin{array}{l}\text { No regulados } \\
\text { en las } \\
\text { condiciones de } \\
\text { prestación. }\end{array}$ & $\begin{array}{l}\text { Altos niveles de } \\
\text { precariedad en las } \\
\text { condiciones } \\
\text { laborales. }\end{array}$ & $\begin{array}{l}\text { Regulados } \\
\text { normativamente. }\end{array}$ & $\begin{array}{l}\text { Poco regulados } \\
\text { normativamente }\end{array}$ & $\begin{array}{l}\text { Regulados } \\
\text { normativamente }\end{array}$ \\
\hline $\begin{array}{l}\text { Derechos laborales } \\
\text { y previdenciarios }\end{array}$ & $\begin{array}{l}\text { No alcanzados } \\
\text { por la } \\
\text { legislación } \\
\text { laboral, ni por } \\
\text { la protección } \\
\text { social (seguro }\end{array}$ & $\begin{array}{l}\text { Altos niveles de } \\
\text { informalidad } \\
\text { contractual. }\end{array}$ & $\begin{array}{l}\text { Alcanzados por } \\
\text { normativas } \\
\text { laborales y de } \\
\text { protección social. }\end{array}$ & $\begin{array}{l}\text { Parcialmente } \\
\text { alcanzados por } \\
\text { normativas } \\
\text { laborales y de } \\
\text { protección social }\end{array}$ & $\begin{array}{l}\text { Alcanzados por } \\
\text { normativas } \\
\text { laborales y de } \\
\text { protección social }\end{array}$ \\
\hline
\end{tabular}

13 Entiéndase por "feminizados" cuando las mujeres son más de la mitad, en valores absolutos, entre quienes prestan esos servicios. 
Rev. Interd. em Cult. e Soc. (RICS), São Luís, v. 6, n. 2, p. 50-71, jul./dez. 2020

ISSN eletrônico: 2447-6498

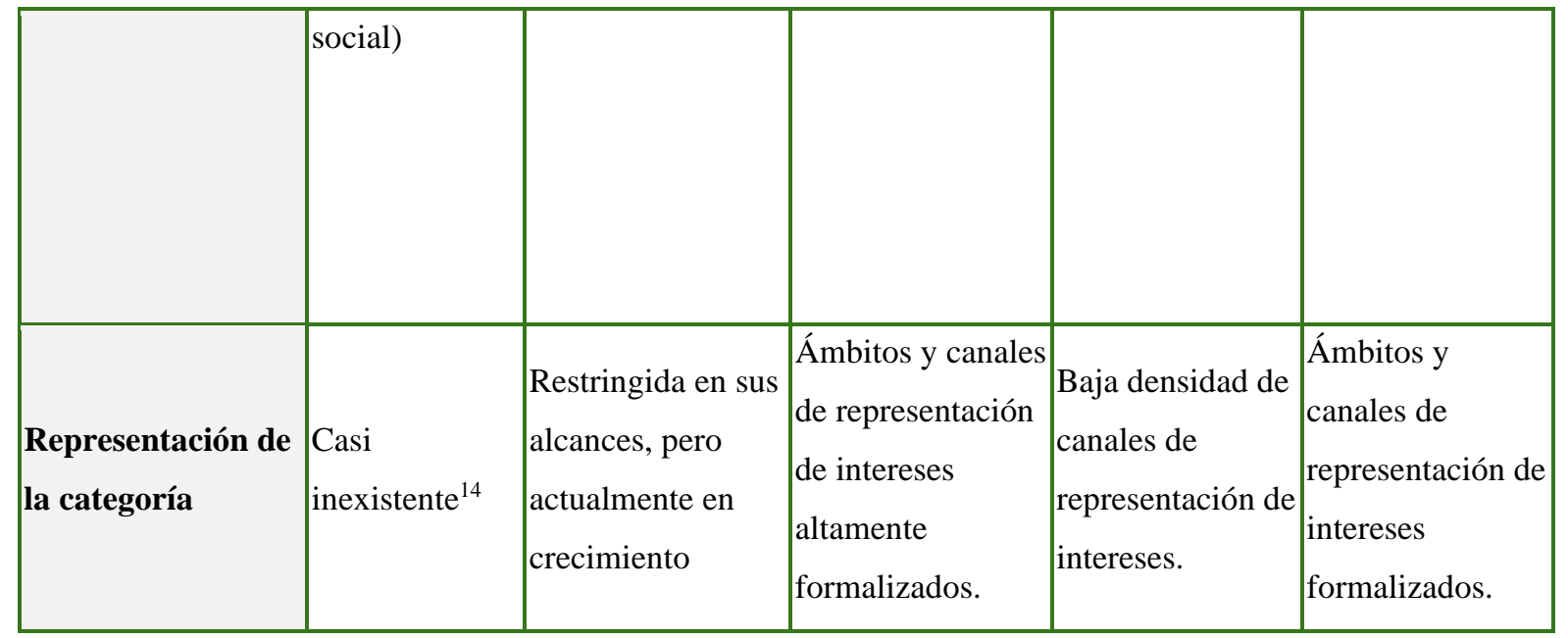

Fuente: Elaboración propia.

La dimensión geopolítica es intrínseca a la crisis global de cuidados ya que la misma se fundamentaría en jerarquías coloniales, raciales, étnicas (p.24) que se reproducen en el trabajo doméstico remunerado tanto en los países del Norte Global como en los propios países del Sur Global, asumiendo en el primer caso la forma de migraciones intercontinentales y en el segundo de migraciones internas nacionales, campo-ciudad, inter e intra urbanas y otras formas de desplazamientos internos, así como transnacionales en enclaves de integración regional como por ejemplo, al interior del bloque MERCOSUR. Transversal y apriorísticamente a todas ellas, tanto en el Norte como en el Sur Global, se encuentran las desigualdades de género (FERRO,2020).

Por esta razón, creo que el estudio de los conflictos y organización de los tiempos de trabajo y de vida nos remite a una cuestión anterior: ¿cómo resuelven las sociedades las necesidades de subsistencia de las personas? O, dicho de otra manera, ¿cómo se organizan en torno a esta función primaria y fundamental de la cual depende nada más ni nada menos que la vida humana? (CARRASCO, 2001:1).

\section{LA RESPUESTA SOTERRADA}

En la revisión más reciente de las proyecciones de población realizada por UN DESA (2020), se afirma que: “Creciendo a un ritmo menor, se espera que la población mundial alcanzará 9.700 millones en 2050 y un máximo de casi 11.000 millones alrededor de 2100”. Pero este crecimiento poblacional está distribuido en forma diferente en el mundo, y algunas regiones como América Latina, especialmente países del área MERCOSUR, a partir de la

\footnotetext{
${ }^{14}$ _Cf para el caso argentino el Sindicato de Amas de Casa de la República Argentina (SACRA), para Brasil Associação das Donas de Casa, para Paraguay la Liga de Amas de Casa y para Uruguay la Liga de Amas de Casa, consumidores y usuarios de la República Oriental del Uruguay.
} 
Rev. Interd. em Cult. e Soc. (RICS), São Luís, v. 6, n. 2, p. 50-71, jul./dez. 2020

ISSN eletrônico: $2447-6498$

mitad del siglo en curso tendrán una marcada disminución de su población. Esto se debe a una fuerte y sostenida caída de las tasas de fecundidad en la región desde las últimas décadas, que proseguirá en esa tendencia a lo largo del corriente siglo, según estimativas.

\section{Gráfico No.2. Tasa de fecundidad y proyecciones en América Latina y países del MERCOSUR. 1950-2100.}

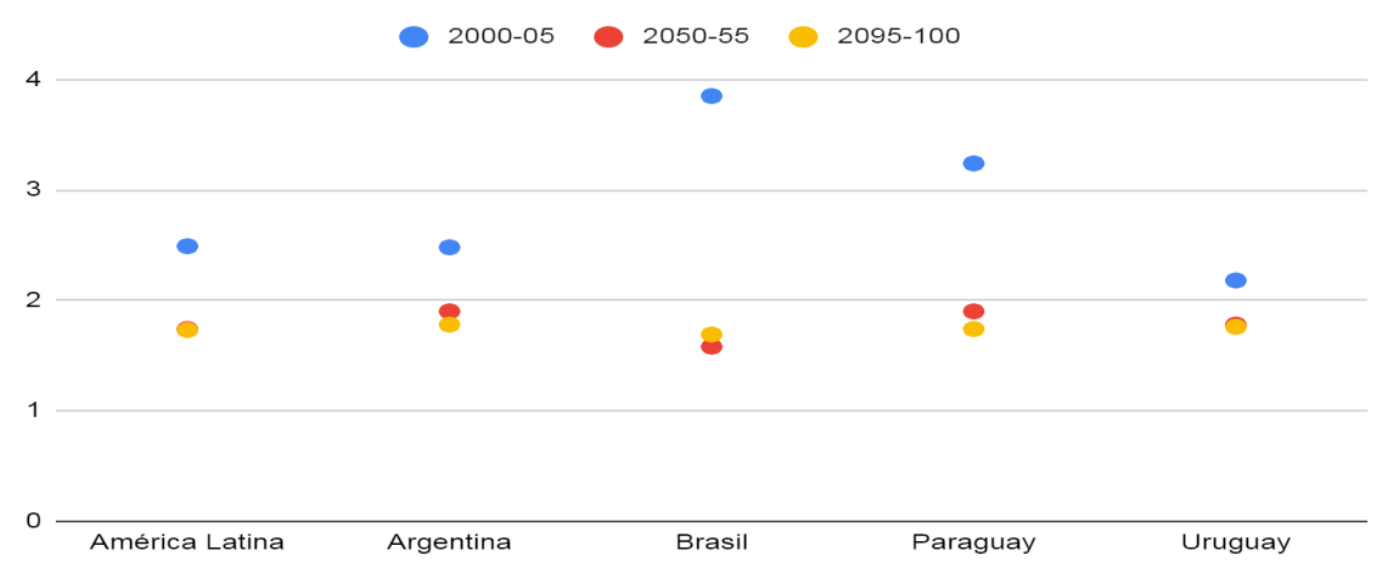

Fuente: Elaboración propia en base a datos de UN DESA (2020). ${ }^{15}$

A su vez, e igual que el resto del mundo, esta región evidencia un sostenido incremento del envejecimiento poblacional por la conjugación de dos factores: la referida caída de las tasas de fecundidad y la extensión de la expectativa de la vida. Esto último gracias a una conjugación de 1) provisión de cuidados no remunerados y remunerados, 2) expansión de los sistemas de protección social, 3) ampliación del alcance del sistema sanitario ${ }^{16}$ y 4) avances científicos y tecnológicos en las ciencias médicas y de la sanidad.

\footnotetext{
15 https://population.un.org/wpp/ acessado e processado em agosto de 2020.

${ }^{16}$ Como la mayoría de las políticas de cuidados existentes en países latino-americanos el Programa "Chile crece contigo", está enfocado en la primera infancia. Disponible en http://www.crececontigo.gob.cl/ Acceso septiembre de 2020
} 
Rev. Interd. em Cult. e Soc. (RICS), São Luís, v. 6, n. 2, p. 50-71, jul./dez. 2020

ISSN eletrônico: 2447-6498

Cuadro No.2 Esperanza de vida al nacer, quinquenio 2020-2025 en países del

MERCOSUR y América Latina, por sexo.

\begin{tabular}{|c|c|c|c|}
\hline Região/ País & Mujeres & Hombres & Totales \\
\hline América Latina & 79,2 & 72,9 & 76,1 \\
\hline Argentina & 80,4 & 73,8 & 77,2 \\
\hline Brasil & 80,1 & 73 & 76,6 \\
\hline Paraguay & 76,8 & 72,6 & 74,6 \\
\hline Uruguay & 81,9 & 74,8 & 78,4 \\
\hline
\end{tabular}

Fuente: Elaboración propia en base a datos de CEPALSTAT

En el envejecimiento poblacional, a diferencia del caso de la franja poblacional comprendida entre 0 y 14 años, considerada usualmente comprendida en las categorías “primera infancia” e “ infancia”, la presión de la demanda de cuidados sobre la población entre 15 y 64 años precisa de algunas relativizaciones pues las mujeres mayores, aún las “medio sanas/medio enfermas" (DURÁN, 2011) siguen proveyendo cuidados a sus parejas hombres, aun cuando ambos estén en las mismas condiciones físicas y mentales, así como también buena parte de ellas continúan proveyendo apoyo al cuidado de nieto/as e hijo/as adulto/as dependientes de cuidados por diferentes razones. Esto altera la creencia de que la solidaridad intergeneracional sería únicamente ascendente, idea en la que se basan, por ejemplo, los sistemas previsionales en gran parte del mundo, cuando, a diferencia de los adultos mayores, en el caso de las mujeres mayores, en muchos casos es de ida, pero en más casos es de vuelta (ascendente y descendente), considerando, inclusive, la dependencia económica (FERRO, 2019).

El peso del déficit de infraestructura pública de cuidados se manifiesta especialmente en los altos índices de feminización de la pobreza, donde hay correlaciones positivas entre cantidad de hijos menores de 5 años, pocos años de capacitación/escolarización y desempleo o en actividades sumergidas en la economía informal: autoempleo y subempleo (CEPALSTAT).Asimismo en el caso de las personas empleadas existe una clara segregación de género cuando se analizan las actividades por el indicador de productividad, indicador sensible a la formación y capacitación escolarizada de empleados y empleadas: 
Rev. Interd. em Cult. e Soc. (RICS), São Luís, v. 6, n. 2, p. 50-71, jul./dez. 2020

ISSN eletrônico: $2447-6498$

Dentro de las personas empleadas en sectores de baja productividad se encuentran aquellas empleadas en la agricultura, que en la región son una de cada diez mujeres ocupadas. Además, comprende también el sector de servicios, que incluye el servicio doméstico, en el que se emplean la mayor cantidad de mujeres latinoamericanas (en promedio el $40.6 \%$ de las ocupadas). (OIG-CEPAL ${ }^{17}$ ).

En los demás quintiles a medida que se va extendiendo la escolaridad-y por ende la inclusión en empleos de alta productividad- cae el número de hijos y aumenta el tiempo de empleo remunerado (CEPALSTAT) y por ende la posibilidad de pagar por servicios de cuidados, el llamado "empleo doméstico". Entre asalariados las brechas de ingreso entre hombres y mujeres, muy expresivas en la región ${ }^{18}$, obedecen menos a los diferenciales formativos como postulan los neoclásicos que al peso del cuidado mal distribuido en los hogares y en la sociedad; como lo evidencia en la región- y en todo Occidente- el ya permanente proceso de feminización de los estudios superiores (UNESCO, 2019).

El déficit del cuidado en cada país, en sus diferentes escalas, puede y debe ser cuantificado sistémicamente, desarrollando matrices de variables e indicadores que den cuenta de cada subsistema como planteado aquí en el Cuadro No 1. Esto va mucho más allá de los cuidados sanitarios que parecen ser actualmente los únicos visibles para las políticas y la opinión pública en nuestros países, cuando en realidad éstos son apenas la punta del iceberg de las prestaciones de cuidados.

\section{LA RESPUESTA DESDE LAS POLÍTICAS}

En el último tercio del siglo pasado comienza a visibilizarse esta crisis de cuidados primero en los países del Norte Global donde la inserción de las mujeres en la educación superior y en el mercado laboral asalariado, fue más rápida y expresiva que en las sociedades del Sur Global las cuales acompañaron el proceso más tardíamente. Ante la falta de democratización paritaria de la corresponsabilidad de cuidados a escala interpersonal y sistémica que demuestran las estadísticas de uso del tiempo, para las mujeres- en cualquier sociedad- resolver exitosamente la transferencia parcial de funciones de cuidado, incide de lleno en la empleabilidad y movilidad ascendente dentro de las organizaciones laborales, sorteando eventualmente las segregaciones verticales y horizontales por razones de género.

\footnotetext{
17 Extraído de oig.cepal.org/es/indicadores/distribucion-la-poblacion-ocupada-segun-nivel-productividad-sexo Acceso septiembre de 2020.

18 "La disminución de 12,1 puntos porcentuales de la brecha entre los salarios de mujeres y hombres entre 1990 y 2014, significa un avance hacia la igualdad salarial en América Latina. Sin embargo, el salario de las mujeres es aún solo el $84 \%$ por ciento de lo que ganan los hombres.” (CEPAL,2016)
} 
Rev. Interd. em Cult. e Soc. (RICS), São Luís, v. 6, n. 2, p. 50-71, jul./dez. 2020

ISSN eletrônico: $2447-6498$

El poder adquisitivo del salario y las crecientes expectativas de consumo no siempre facilitan la posibilidad de sustituir servicios de cuidado intrafamiliares por la contratación $a d$ hoc. Una solución más barata que contratar mujeres connacionales más pobres fue hacerlo con mujeres migrantes del sur global que tendrían menos accesibilidad a derechos laborales y a situaciones contractuales claras en ese tipo de prestaciones.

Estas migrantes internacionales también fueron una solución más barata para los gobiernos del Norte Global, que sin ellas deberían invertir fondos y responsabilizarse en expandir y mejorar la infraestructura pública de servicios de apoyo a los cuidados ante la creciente demanda. Estos flujos migratorios fueron incentivados directamente por la facilitación de políticas migratorias ex profeso, que intentaron así responder a la situación sin que el problema trascienda del ámbito de los hogares. También, en algunos casos nacionales, se intentó responder con subsidios, insuficientes para pagar ese tipo de servicios en los mercados nacionales (WILLIAMS, 2011) ya través de deducciones impositivas. El conjunto de medidas que podríamos llamar de "respuesta" desde las políticas públicas a esta crisis también se evidenció en países del Sur Global y en conjunto podrían clasificarse de la siguiente manera, sin agotar inventario.

Cuadro No. 2. Clasificación de políticas de cuidados según locación de recursos. (algunos ejemplos)

\begin{tabular}{|lr|l|l|}
\hline \multicolumn{2}{|c|}{ Tiempo } & \multicolumn{1}{|c|}{ Ingresos } & \multicolumn{1}{|c|}{ Servicios públicos } \\
\hline Licencias parentales & $\begin{array}{l}\text { Programas de Transferencias } \\
\text { Monetarias Condicionadas. }\end{array}$ & $\begin{array}{l}\text { Cuidados de Infancia en instituciones } \\
\text { laborales (guarderías) }\end{array}$ \\
\hline $\begin{array}{l}\text { Flexibilización horaria en el } \\
\text { ámbito laboral. }\end{array}$ & palario familiar & $\begin{array}{l}\text { Alimentación y otros cuidados provistos } \\
\text { mediante el sistema educativo. }\end{array}$ \\
\hline $\begin{array}{l}\text { Reducciones horarias } \\
\text { cuidados. }\end{array}$ & tributos. & $\begin{array}{l}\text { Hogares de huérfanos, de ancianidad, } \\
\text { espacios institucionales de inclusión de } \\
\text { personas con discapacidad, entre otros. }\end{array}$ \\
\hline
\end{tabular}

Fuente: Elaboración propia en base a BATTHYANY, GENTA y SCAVINO (2018)

Si bien no todas asumen el nombre genérico de políticas de cuidados, su función es proveerlo. En este sentido podemos constatar que ya existen en la mayor parte de los países latino-americanos algunas políticas de este tipo, las cuales con décadas de existencia normativa siguen aún sin generalizarse para responder adecuadamente a las demandas existentes. Un caso particular son las guarderías infantiles que son un derecho de la población 
Rev. Interd. em Cult. e Soc. (RICS), São Luís, v. 6, n. 2, p. 50-71, jul./dez. 2020

ISSN eletrônico: 2447-6498

trabajadora aun cuando se hicieran en función de facilitar el acceso de las madres al trabajo asalariado. Una guardería en cada organización donde se presten servicios laborales que ultrapase cierto número de empleadas, como se enunciaron inicialmente y recientemente más incluyentes considerando tanto el número de empleados y empleadas indistintamente-ambos serían prima facie responsables de los cuidados de sus infantes- son ya "viejas" conquistas de las organizaciones del trabajo asalariado. Sin embargo, su incumplimiento es todavía significativo incluyendo en esto a muchas de las propias organizaciones estatales.

Más recientes son las conquistas de ampliación de licencias parentales para los padres, y de flexibilización horaria, en general el conjunto de medidas llamadas de "conciliación" entre la vida laboral y familiar, aun cuando estas medidas siguen sesgándose sobre las trabajadoras. En suma, son medidas insuficientes y no articuladas en la mayor parte de los países aquí considerados. En otro sentido, Uruguay avanza hacia esta articulación y mejoramiento de respuesta desde las políticas públicas creando en el año 2015 un Sistema Nacional de Cuidados, transversal a todos los ministerios y políticas existentes.

En Uruguay el cuidado es tanto un derecho como una función social garantizada por la Ley $\mathrm{N}^{\mathrm{o}}$ 19.353. El Sistema de Cuidados nace con el objetivo de generar un modelo de responsabilidad compartida de los cuidados, entre familias, Estado, comunidad y mercado [...] El cuidado atraviesa la vida de todas y todos: somos cuidados al inicio de nuestras vidas, cuidamos a nuestros hijos e hijas, a nuestros familiares mayores y quizás necesitemos cuidados al envejecer. La resolución del cuidado siempre ha estado relegado al ámbito privado de cada familia, según su disposición de tiempo y capacidad de compra, lo cual profundiza desigualdades. ${ }^{19}$ "

Podría inferirse una correlación positiva entre los países latinoamericanos que comenzaron a plantearse políticamente este tema, respondiendo desde el sistema público como Chile, Costa Rica y Uruguay (BATTYANI,2015) y el exiguo tamaño de sus poblaciones. Un país de tamaño medio como Argentina comenzó- casi al mismo tiempo que la declaración de la pandemia- a plantearse este tipo de políticas en el más alto nivel decisorio creando en diciembre de 2019 con el recambio presidencial, el Ministerio de las Mujeres, Género y Diversidad y en su estructura funciona una Dirección Nacional de Cuidados.

Con la pandemia, la gran mayoría de los servicios de cuidado incluidos en las llamadas "políticas de respiro familiar" es decir, la infraestructura y servicios públicos de apoyo a los cuidados para menores, ancianidad, discapacidad, rehabilitación y otras situaciones de dependencia acompañadas por instituciones, prácticas de cuidados superpuestas a las políticas educativas, entre otras del mismo tenor; cerraron sus puertas

19 Disponible en https://www.gub.uy/sistema-cuidados/institucional/creacion-evolucion-historica Acceso en septiembre de 2020. 
Rev. Interd. em Cult. e Soc. (RICS), São Luís, v. 6, n. 2, p. 50-71, jul./dez. 2020

ISSN eletrônico: $2447-6498$

preventivamente o limitaron sus servicios drásticamente. Por lo tanto, si lo existente antes de la pandemia era claramente insuficiente y no articulado, con la pandemia el déficit sólo se profundiza agravando la sobrecarga de cuidados al interior de los hogares, es decir mayormente sobre las mujeres integrantes de los mismos.

\section{QUO VADIS? A MANERA DE CONCLUSIONES}

En las emergencias, sea por guerras, desastres ambientales, crisis sanitarias o de otro tenor, la cotidianeidad del funcionamiento de las sociedades afectadas se altera severamente. Para los derechos y oportunidades de las mujeres especialmente, su situación corre más peligro en la reanudación de la normalidad que en la emergencia en sí. Porque las "nuevas normalidades" post crisis conllevan mudanzas programáticas de larga duración y es en esa etapa cuando se corre mayor riesgo de sedimentar e institucionalizar retrocesos.

Los cambios, en el sentido de la democratización de las responsabilidades del cuidado familiar entre hombres y mujeres, tanto en el plano interpersonal como en el sistémico entre familias, estados y sector privado se muestran excesivamente lentos y graduales, así como extremadamente vulnerables a su reversión ante cualquier situación de estrés social sistémico como lo es esta pandemia. La "vuelta al hogar" de las mujeres está siempre acechando a la vuelta de la esquina. En realidad, el mayor acceso de las mujeres a los espacios públicos no implicó que pudieran “dejar atrás el hogar"-es decir a la exclusividad ${ }^{20}$ de sus funciones culturalmente asignadas o al menos repartirlas paritariamente con los hombres adultos con quienes comparten esos hogares, sino que se lo llevan puesto a sus ámbitos de actuación extra-domésticos.

Este permanente llamamiento a la vuelta al hogar de las mujeres ${ }^{21}$, que se hace en forma explícita desde algunos grupos religiosos, la publicidad, grupos políticos conservadores y hasta discursos provenientes de la medicina y de la sanidad, fue contestado explícita o soterradamente, tanto en forma individual como organizada, por constantes actos públicos y

\footnotetext{
20 Actualmente las mujeres dedicadas exclusivamente a "labores del hogar" en todo el mundo están en drástica disminución. Según las últimas mediciones disponibles, en Brasil y Paraguay declararon esta situación el 15\% de las mujeres, en Uruguay el 12\% y en Argentina 11,1\% (CEPALSTAT, últimos datos disponibles por país).

${ }^{21}$ El libro The Handmaid's Tale, con cuyo argumento se hace analogía prospectiva en este trabajo, se publicó en 1985 por primera vez. En tal contexto, las olas conservadoras que arreciaron en los ' 80 intentaron clausurar las décadas de insurrección en la agenda de costumbres y moralidad en Occidente que significaron los ' 60 y ' 70 . En ese contexto se comenzaron a discutir las primeras evidencias de transición demográfica en esas sociedades.
} 
Rev. Interd. em Cult. e Soc. (RICS), São Luís, v. 6, n. 2, p. 50-71, jul./dez. 2020

ISSN eletrônico: 2447-6498

privados de disconformidad con el orden existente ${ }^{22}$ y de propuestas superadoras, aunque no necesariamente articulados y coordinados entre sí en cada caso. La pandemia consiguió, finalmente, la vuelta al hogar de las mujeres. No solo por la mayor presencia física de las mujeres dentro de los hogares, y también de los hombres, sino porque estas superponen dentro de los hogares la mayor parte de las funciones y actividades que antes de la pandemia se repartieron un poco más entre los espacios extra domésticos y domésticos.

En el escenario pandémico, ni siquiera la educación obligatoria de los menores de edad consigue ser compartida con las instituciones educativas, estatales o privadas. En la mayoría de los países afectados del mundo y de América Latina, las madres de escolares reciben los contenidos educativos- en el mejor de los casos- y deben ellas dar cuenta casi en exclusiva de la enseñanza escolar en casa. El homeschooling- en el caso de las mujeres más escolarizadas- ahora se suma, entre otras muchas demandas coyunturales, profundizando al preexistente y desigual reparto de los trabajos y responsabilidades domésticas y familiares. Por ello, es la salida de la crisis sanitaria global la que presenta las oportunidades reales de avance o reversión de la agenda reivindicativa de democratización de las responsabilidades de cuidados, tanto en escala interpersonal como sistémica.

Por ello, en esta comunicación, utilizando el análisis prospectivo, sobre las posibles "nuevas normalidades" que se sucedan a este periodo emergencial, se hace analogía con la sociedad distópica planteada en la novela El cuento de la criada (The Handmaid 's Tale) de la escritora canadiense Margaret Atwood, publicada en 1985. La protagonista de la historia, Offred ("pertenece a Fred"), cuenta en primera persona su vida en Gilead, un gobierno totalitario teocrático instalado en los Estados Unidos en un futuro no especificado. La narración presenta un futuro distópico donde hay un grave problema global de infertilidad. En aquella sociedad las castas sociales estrictas y exclusivas para las mujeres son fácilmente distinguibles por el color de las ropas que se les imponen. Offred es una de las mujeres destinada y forzada a tener hijos para familias de alto rango en el gobierno de Gilead. La protagonista escribe su historia, aun cuando las actividades intelectuales están prohibidas a las mujeres y sin saber si alguien va a leer su testimonio.

Pero también y en sentido opuesto, el futuro próximo está también disponible para la profundización de las agendas reivindicativas de movimientos feministas, ambientales y de derechos humanos y no humanos en general, que consigan colocar el bienestar humano- sin

\footnotetext{
22 Existe literatura sobre este cuestionamiento mucho más antigua que las olas feministas en sí desde la Revolución Francesa en adelante. Por ejemplo, el caso de La ciudad de las Damas de Cristine de Pisan publicada en el siglo XIV y de numerosas publicaciones de religiosas.
} 
Rev. Interd. em Cult. e Soc. (RICS), São Luís, v. 6, n. 2, p. 50-71, jul./dez. 2020

ISSN eletrônico: 2447-6498

condicionamientos- en el centro de la legitimidad, y como orientación principal del Estado y del sector privado para llegar a un nuevo ethos civilizatorio y programático: los Estados del Cuidado. En las zonas medias del espectro de posibilidades, entre Gilead y los Estados del Cuidado; un conjunto amplio de soluciones posibles, muy probablemente incorporarán los matices de ambos escenarios. En ese sentido democratizar y articular los sistemas de cuidados es su consecuencia procedimental y permitiría igualmente prevenir el peligro, para las mujeres contemporáneas, que la distopía de Margaret Atwood se torne profecía.

\section{REFERENCIAS}

AMORÓS, C. Globalización y orden de género. In: AMORÓS, Celia e DE MIGUEL, Ana (Ed.) Teoría Feminista: de la Ilustración a la Globalización. Minerva Ediciones, Madrid, 2005, p.301-332.

ATWOOD, M. The Handmaid's Tale. London: Vintage, 1985.

BATTHYANI, K. Las políticas y el cuidado en América Latina. Una mirada a las experiencias regionales. Serie Asuntos de Género. Santiago de Chile: CEPAL-AECID, 2015.

BATTHYANY, K; GENTA, N. y SCAVINO, Sol. Análisis de género de las estrategias de cuidado infantil en Uruguay. Cadernos de pesquisa. v.47 n.163 p.292-319 jan./mar. 2017.

BECKER, G. Tratado sobre la Familia. Editorial Alianza Universidad, Madrid,1987.

CARRASCO, C. ¿La sostenibilidad de la vida humana, un asunto de mujeres? Revista Mientras Tanto, No 82. Barcelona: Icaria Editora, 2001.

CZERESNIA, D. Do contágio à transmissão ciência e cultura na gênese do conhecimento epidemiológico. Rio de Janeiro: 1997.

DIAMOND, J. Armas, germes e aço. Os destinos das sociedades humanas. Rio de Janeiro: Editorial Record, 2013.

DURÁN, M. A. El trabajo del cuidado en el marco macroeconómico. In: DURÁN, María de los Ángeles (Dir.) El trabajo de cuidado en América Latina y España. Madrid: Fundación Carolina-CeALCI, pp11-32, 2011.

FERRO, S.L. Crisis global de cuidados, migraciones transnacionales y remesas Impactos en y desde América Latina. Cidades, comunidades e territórios. N.40, pp 88-102, 2020.

FERRO, S.L. El cuidado como posibilidad de realización del paradigma de la universalidad y la solidaridad en los sistemas públicos de cuidados de protección social. Revista

Interdisciplinaria de Estudios Sociales, pp 41-81,2019. 
Rev. Interd. em Cult. e Soc. (RICS), São Luís, v. 6, n. 2, p. 50-71, jul./dez. 2020

ISSN eletrônico: 2447-6498

FERRO, S.L. Economía del cuidado. Debates conceptuales e implicancias políticas. In: DELICH, F y DE PABLO, J.C.(Coord.) Economía, Política y sociedad. Smith, Ricardo. Marx, Keynes, Schumpeter, Prebisch. Córdoba: Comunicarte, pp 121-138, 2017.

GÁLVEZ, T. Discriminación de género en el mercado laboral de América Latina: La brecha de ingresos 2001. In: TODARO, R; GODOY, L. y ABRAMO, L. Trabajo decente y equidad de género en América Latina. Santiago de Chile: OIT, 2006, p.95-127.

HARARI, Y. N. Sapiens. Uma breve história da humanidade. Porto Alegre: L\&PM Editores, Colección Pocket, 2018.

HRSA Sex, Race, and Ethnic Diversity of U.S. Health Occupations (2011-2015). USA: Department of Health and Human Services, 2017.

LARRAITZ, L; ARTZA M. J; CHAVES GROH A; CARCEDO CABAÑAS A.S. La brecha salarial entre hombres y mujeres en América Latina en el camino hacia la igualdad salarial. Ginebra: OIT.

LOVELL, G. y COOK, N. Desenredando la madeja de la enfermedad. In: LOVELL, G. y COOK, N. (Coord.) Juicios secretos de Dios. Epidemias y despoblación indígenas en Hispanoamérica colonial. Quito: Editorial Abya Yala, 2000.

UN CEPAL. La pandemia del COVID-19 profundiza la crisis de los cuidados en América Latina y el Caribe. 2020. Disponible en https://www.cepal.org/es/publicaciones/45335-lapandemia-covid-19-profundiza-la-crisis-cuidados-america-latina-caribe Acceso en septiembre de 2020.

NU CEPAL, OIT, UN WOMEN. Trabajadoras remuneradas del hogar en América Latina y el Caribe frente a la crisis del COVID-19, 2020. Disponible en https://www.cepal.org/es/noticias/la-situacion-precariedad-trabajadoras-domesticas-americalatina-caribe-se-acentua-frente-la Acceso en septiembre de 2020.

UN CEPAL Nota para la igualdad $\mathrm{N}^{\circ}$ 18: Persiste la brecha salarial entre hombres y mujeres, 2016. Disponible en https://oig.cepal.org/es/notas/nota-la-igualdad-ndeg-18-persistela-brecha-salarial-hombres-mujeres Acceso en septiembre de 2020.

PARELLA RUBIO, S. La maternidad a distancia de las empleadas domésticas latinoamericanas en España. La vulneración del derecho a la vida familiar en el contexto de la "internacionalización de la reproducción. In: GIRO, Joaquín (ed.) El género quebrantado. Sobre la violencia, la libertad y los derechos de la mujer en el nuevo milenio. Editorial Catarata. Madrid,2005.

PÉREZ OROZCO, A. Amenaza tormenta: la crisis de los cuidados y la reorganización del sistema económico. Revista de Economía Crítica, №. 5, 2006, págs. 7-37.

PICCHIO, A. (2009) Condiciones de vida, perspectivas, análisis económico y políticas públicas. Revista Economia Critica N ${ }^{\circ} 7$ primer semestre 2009, pp27-54.

DE REZENDE, J.M. Epidemia, Endemia, Pandemia, Epidemiologia. Linguagem Médica, Vol. 27(1): 153-155.jan-jun. 1998. 
Rev. Interd. em Cult. e Soc. (RICS), São Luís, v. 6, n. 2, p. 50-71, jul./dez. 2020

ISSN eletrônico: 2447-6498

ROMERO, M. Reflections on Globalized Care Chains and Migrant Women Workers.

Critical Sociology, Vol. 44, p. 1179-1189,2018.

SCOTT, J. Genero. Una categoría útil para el análisis histórico. In: LAMAS, Marta (Comp.) El género. La construcción cultural de la diferencia sexual. PUEG. México.1996.

TURNER, Brian. Corpo e Sociedade. Estudos em Teoria Social. São Paulo: Ideias e Letras Edições, 2014.

UNITED NATION DEPARTMENT OF ECONOMICS AND SOCIAL AFFAIRS. World Population Prospects. The 2019 revision. New York: UN DES,2020.

UNESCO. Descifrar el código: La educación de las niñas y las mujeres en ciencias, tecnología, ingeniería y matemáticas (STEM). Ginebra: Naciones Unidas, 2019.

UN WOMEN. Alerta de género para brote de COVID-19. New York: Grupo de Referencia sobre Género en Acción Humanitaria (IASC), 2020.

WHO. Constitución de la Organización Mundial de la Salud. Documentos básicos, 2006. Disponible en https://www.who.int/governance/eb/who_constitution_sp.pdf Accesado en septiembre 2020.

WHO, Preguntas y respuestas: violencia contra la mujer durante la pandemia de COVID-19, 2020. Disponible en https://www.unwomen.org/es/news/stories/2020/4/statement-edphumzile-violence-against-women-duringpandemic?gclid=Cj0KCQjwqfz6BRD8ARIsAIXQCf0rxx47WBg9aibeA8xSPnLAHaw2DOmEZjzjF106ynJPmlQIGMh-nAaAvxFEALw_wcB Accesado en septiembre de 2020.

WILLIAMS, F. Markets and migrants in the care economy: caring in the rich parts of the world is now an industry and one that is heavily dependent on low-paid workers from the global south. Soundings, no. 47, Gale Academic OneFile. Disponible en https://linkgale.ez350.periodicos.capes.gov.br/apps/doc/A287518262/AONE?u=capes\&sid=AONE\&xid $=\mathrm{c} 32 \mathrm{cbc} 2 \mathrm{c}$. Acceso en agosto 2020. 